\title{
VERSUS: A BUSCA POR UMA IDENTIDADE CULTURAL LATINO-AMERICANA
}

\author{
Xenya de Aguiar Bucchioni ${ }^{1}$ \\ Juliana Sayuri Ogassawara ${ }^{2}$
}

\begin{abstract}
Resumo: Data de 1975 o nascimento do jornal alternativo Versus, imerso na proposta de publicar aventuras, idéias, reportagens e principalmente cultura, assumindo neste último pilar um forte caráter de resistência. Nas páginas de Versus encontra-se um discurso épico das tramas latino-americanas, com seus heróis e sua realidade fantástica, que no jornal ganhava matizes metafóricos para expressar o horror das ditaduras instauradas na América Latina da década de 1970. Neste artigo, pretendemos resgatar a memória de Versus, discutindo ainda a atuação do jornal na composição das identidades latino-americanas.
\end{abstract}

Palavras-chave: América Latina. Imprensa Alternativa. Ditadura Militar. Resistência. Versus.

\begin{abstract}
First released in 1975, the alternative newspaper Versus had a distinguished proposal to publish adventures, ideas and reportages that, from a cultural point of view, build up a strong sense of resistance. Among its pages, an epical Latin American discourse can be found, with its heroes and fantastic reality, narratives that actually addressed, in a metaphorical way, the horrors of Latin American's dictatorships from the period. This article will bring back the memory of Versus and discuss the role of this journal in the construction of Latin American identity.
\end{abstract}

Key-words: Latin America. Alternative press. Dictatorship. Resistence. Versus.

\section{Versus, um jornal de aventuras, idéias, reportagens e cultura}

Versus nasceu em 1975, no auge da imprensa alternativa brasileira (1975-1977), uma experiência jornalística efervescente durante a asfixia da ditadura militar (1964-1985). Debruçado sobre as questões da América Latina, o tablóide trazia um novo viés sobre a cultura, tateando uma identidade latino-americana. Na esteira dos jornais alternativos, Versus

\footnotetext{
${ }^{1}$ Jornalista, mestranda do Programa de Pós-Graduação em Comunicação Midiática (UNESP) e integrante do Grupo de Pesquisa Mídia e Sociedade (CNPq).

E-mail: xenya_aguiar@yahoo.com.br

${ }^{2}$ Jornalista e mestranda em História Social na Faculdade de Filosofia, Letras e Ciências Humanas da Universidade de São Paulo (FFLCH-USP).

E-mail: j-sayuri@usp.br
} 
abria caminho para mais uma via possível ao jornalismo brasileiro, alinhando-se à "imprensa alternativa”, durante o Estado Autoritário, um momento em que "a imprensa sai de cena como ‘palmatória do mundo’ e ocupa o incômodo banco dos réus” (AQUINO, 1999, p. 157).

É nesse enquadre contextual que se via o surgimento da imprensa alternativa (Pereira, 1986). À época, essa imprensa era como "um fogo-fátuo a iluminar as zonas obscuras do autoritarismo. Ela vive, ou sobrevive, nos regimes fechados em que o poder estabelece um controle cerrado do sistema de comunicação” (CAPARELLI, 1980, p. 41). A partir dessa perspectiva histórica do fenômeno alternativo, a atmosfera sufocante da censura e da repressão às atividades culturais e intelectuais atiçava ainda mais a busca por espaços para respirar novas ideias, inspirar transformações políticas e transpirar em manifestações sócioculturais. Na emboscada entre a ditadura e a grande imprensa complacente, era preciso encontrar brechas para respirar:

Brechas numa rede que estava sendo jogada. Por meio delas, iriam surgir os primeiros brotes da chamada imprensa alternativa. Espaço que se queria livre não apenas dos constrangimentos da ditadura, mas também das orientações dos donos dos grandes jornais (REIS, 2002, p. 441).

Portanto, além do tenebroso espectro político, é preciso considerar que a indústria cultural e a grande imprensa - ilustrada pelos conglomerados Globo e Abril e pelos jornais Folha e $O$ Estado de S. Paulo - evidenciam sua consolidação no Brasil na década de 60 (TASCHNER, 1992, p. 17).

Assim, foi nos marcos de um capitalismo monopolista tardio e sob a égide de um regime político autoritário de controle militar, no qual boa parte dos direitos de cidadania foram restringidos ou inexistentes, que a indústria cultural viveu um período de grande desenvolvimento, o qual, em função de tal enquadramento, ganharia certa especificidade (TASCHNER, 1992, p. 105).

O início da indústria cultural brasileira se afinou com o período ditatorial, porém, por outro lado o momento histórico abarcou ainda o florescimento da "imprensa alternativa”, que de 1964 a 1980 prosperou e sucumbiu com cerca de 150 periódicos.

Lato sensu, a definição de "imprensa alternativa” abriga as publicações nas quais é presente a resistência contracultural (MICCOLIS, 1986, p. 3). Aglutinando intelectuais, jornalistas e setores de esquerda, a imprensa alternativa - designada ainda marginal, contracultural, "nanica, de leitor, independente e underground” (CHINEM, 1995, p. 7) -, era também um novo espaço de articulação social. Distante das políticas dominantes, encontrava- 
se na imprensa alternativa o desejo das gerações de 1960-1970 de protagonizar as transformações sociais de seu tempo.

Gerações que “opunham-se por princípio ao discurso oficial” (KUCINSKI, 1991, p. XIII), articulando ainda “o desejo das esquerdas de protagonizar as transformações institucionais que propunham e a busca, por jornalistas e intelectuais, de espaços alternativos à grande imprensa e à universidade” (KUCINSKI, 1991, p. XVI). Assim, "resistência” era a palavra de ordem contra a ordem ditatorial e a grande imprensa predominante. Com essa palavra-chave, Versus se insere no fenômeno alternativo. Em outubro de 1975, alavancado pela mente inventiva de Marcos Faerman:

[...] Versus nasceu de um delírio que eu tive em Cuiabá... Eu havia ido ao Mato Grosso fazer uma matéria para o JT e conheci Juruna... Cuiabá é o centro geodésico da América do Sul, o pôr-do-sol me encheu de emoção; me apaixonei pela idéia de um jornal que falasse dos índios, da América Latina, que tivesse aquele pôr-do-sol. Sonhei com um jornal que contasse a história dos povos da América Latina... que fosse realidade e ficção, de grandes histórias, narradas como histórias, e havia o fascismo na América Latina, havia Chile, eu queria um jornal que contasse a história da resistência na América Latina [...] (KUCINSKI, 2003, p. 254).

No ínterim de 1975 a 1979, foram lançadas as 34 edições de Versus. Inicialmente, o tablóide bimestral era modestamente vendido de mão em mão, mas aos poucos passou a ser distribuído em bancas de jornal de São Paulo, Rio de Janeiro, Porto Alegre e outras cidades. Uma vez consolidada sua distribuição nacional, no seu apogeu em 1977, o jornal alternativo superou a marca de 35 mil exemplares vendidos, "graças, sobretudo, à originalidade e beleza de cada edição” (KUCINSKI, 2003, p. 250).

Marcos Faerman estreou no jornalismo em 1961, no jornal Última Hora, que se tornaria o Zero Hora. Lá, ao lado de Luís Fernando Veríssimo, o jornalista criou um Caderno de Cultura, que já continha o gérmen criativo do que seria o projeto Versus. Passando pelo Jornal da Tarde e por publicações alternativas como Bondinho, Ex e Mais Um, Faerman buscava abrir um espaço para a grande reportagem.

Descontente com a burocratização do jornalismo, Faerman imprimia em Versus a defesa constante de um jornal desgarrado de fórmulas e modelos, mas alinhado à clareza e precisão da reportagem. Além dele, importantes personagens da criação do jornal foram os jornalistas Moacir Amâncio, Percival de Souza, Wagner Carelli, Enio Squeff, Omar de Barros Filho (BARROS FILHO, 2007). Depois vieram compor a equipe o jornalista Caco Barcellos e os intelectuais Bóris Schnaiderman e Modesto Carone. 


\section{Três Versus}

A trajetória do jornal é marcada por três fases: inicialmente, a linha editorial se voltava

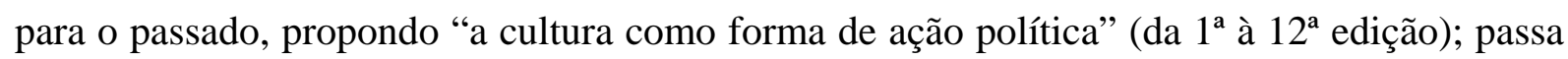
depois por uma fase de transição, dando mais ênfase à situação presente (12a à $24^{\mathrm{a}}$ edição), época em que publica o caderno dedicado à questão negra, "Afro-Latino-América”, que se tornou um espaço de aglutinação de militantes do movimento negro; finalmente, após claramente assumir o discurso politizado, o jornal passa a discutir a política nacional $\left(24^{\mathrm{a}}\right.$ à $34^{\mathrm{a}}$ edição).

Pretendemos esquadrinhar uma análise de Versus, sobretudo em sua fase inicial e, portanto, brevemente perpassaremos os pontos principais de sua transição e de seu fim. É preciso lembrar que o declínio e o fim da imprensa alternativa são usualmente justificados pelo fim da própria ditadura, como se "sua única razão de existir fosse a resistência" (KUCINSKI, 1991, p. XXV). Entretanto:

Além disso, é interessante atentar para o que a memória construiu em relação à imprensa alternativa. Ela vinculou umbilicalmente este tipo de jornalismo à censura, justificando o término de sua fase áurea com base na hipótese da inexistência de motivações para a sua continuidade, a partir da extinção da repressão (AQUINO, 1999, p. 23).

Para além da redemocratização, na verdade, o que fez a imprensa alternativa definhar foi uma série de fatores truncados, dentre os principais estão: a debilidade econômica dessa imprensa que, marcada por uma aversão à estrutura capitalista, não atentava para a administração financeira; a dispersão dos jornalistas, intelectuais e ativistas políticos com a abertura política, o que tornou difícil manter unidas as diferentes vertentes esquerdistas, pois os partidos não precisavam mais conviver na imprensa, lançando cada um o seu próprio meio de comunicação; a imprensa tradicional investiu por um curto tempo na experiência do jornalismo considerado "crítico”, antes monopólio da alternativa. Jornais de ampla circulação como O Pasquim, Versus e Em Tempo optaram pela circulação nacional via Editora Abril, mas as grandes distribuidoras impunham aos jornaleiros o pagamento adiantado pelas cotas de jornal que recebiam, além de se apoderarem de $40 \%$ da receita, fato que financeiramente debilitava ainda mais os alternativos.

Mais um fator a ser lembrado é o sectarismo ideológico no interior das redações, expressado em divergências político-partidárias e ideológicas para os rumos tanto do jornal quanto do País. Há de se frisar que os atores sociais durante o “fazer jornalístico”, no entanto, 
procuram atingir alvos que "são definidos antes da luta, mas o próprio movimento da história os leva, muitas vezes, a mudar de rumo” (CAPELATO, 1994, p. 13) e este seria o caso dos desvios trilhados pelos principais personagens da imprensa alternativa, que durante o ofício jornalístico foram levados a caminhos diversos e por vezes divergentes com o desenrolar dos acontecimentos históricos.

Ao enfocar as questões políticas e, portanto, se politizar efetivamente Versus perde sua linha-mestra inicial. Destacamos que, em um primeiro momento, Faerman foi simpatizante do movimento da Liga Operária, mas sua inclinação brizolista o levava para caminhos opostos aos de seus companheiros. Ao mesmo tempo em que abriu espaço à notícia do lançamento do movimento Convergência Socialista, lançado pela Liga, Faerman concedeu amplos espaços a Brizola, “o herói de seu imaginário, o chefe da resistência gaúcha contra o golpe, o idealizador e comandante da campanha pela legalidade” (KUCINSKI, 2003, p. 263).

Após as prisões de militantes da Convergência, Faerman decide abandonar o jornal, acompanhado por Vitor Vieira, Evaldo Lins, Mário Augusto Jacobskind e outros. Jorge Pinheiro, Omar de Barros Filho, Enio Bucchioni e Júlio Tavares ainda publicam nove edições do jornal - a última sairia em outubro de 1979.

Ao revisitar a trajetória histórica de Versus, pretendemos discutir a atuação da imprensa, considerando que:

\footnotetext{
Manancial dos mais férteis para o conhecimento do passado, a imprensa possibilita ao historiador acompanhar o percurso dos homens através dos tempos [...] Através dela se trava uma constante batalha pela conquista dos corações e mentes - essa expressão de Clóvis Rossi define bem a atividade jornalística. Compete ao historiador reconstituir lances e peripécias dessa batalha cotidiana na qual se envolvem múltiplos personagens (CAPELATO, 1994, p. 13).
}

Diante disso, ao enfatizar os traços culturais do projeto Versus buscamos delinear lances e peripécias na composição de uma identidade cultural, a partir de um jornal que se aventurava pelas palavras: “reportagens, idéias e cultura”.

\section{Em busca de alternativas: Versus e a contra-cultura}

As palavras "versus” e "contracultura” apresentam um ponto de encontro: a oposição. Não só pelo título estampado, mas por suas tentativas de oposição, contestação e resistência, Versus se alinha às experiências alternativas no campo cultural na década de 1970, principalmente após o processo de abertura democrática. Mediante o discurso político, a 
ruptura com valores tradicionais, o uso de novas construções lingüísticas e a desconstrução da arte canonizada, os movimentos culturais das décadas de 60 e 70 propunham novas formas de “fazer cultural”, diferenciando-se da cultura oficial.

Muitas destas experiências manifestavam não só a tentativa de fazer chegar ao público sua produção, mas, e principalmente, expressavam opções de resistência política e ideológica, a presença de novas concepções na forma e no conteúdo, a busca de novas práticas coletivas num tempo de mudanças (HABERT, 1996, p. 77).

Bernardo Kucinski enquadra Versus (São Paulo) como representante da vertente existencial e contracultural da imprensa alternativa, ao lado de O Pasquim e Flor do Mal (Rio de Janeiro), Verbo Encantado (Salvador), Pato Macho (Porto Alegre), isto é, jornais:

Mais voltados a crítica dos costumes e a ruptura cultural, tinham suas raízes nos movimentos de contra-cultura norte-americanos e, através deles, no orientalismo, no anarquismo e no existencialismo de Jean Paul Sartre. Investiam principalmente contra o autoritarismo na esfera dos costumes e o moralismo hipócrita da classe média (KUCINSKI, 1991, p. XV).

No editorial comemorativo ao primeiro aniversário do jornal, fica expresso o projeto cultural e político idealizado:

Um jornal sem vergonha de assumir a reflexão e a cultura, num momento em que, na grande imprensa, Letras, Artes e Pensamento eram relegados à condição de "variedades". Ao mesmo tempo, não sentíamos Versus como "uma revista literária". (Alguma vezes, assim fomos chamados - e isso nos aborreceu). Nem como uma revista "cultural". Talvez porque nosso conceito da literatura e da cultura nos conduzisse a outros caminhos (VERSUS, outubro de 1976, p. 2).

Para Festa, a imprensa alternativa dos anos 70 era marcada por:

[...] publicações de caráter cultural, político e expressavam interesses da média burguesia, dos trabalhadores e da pequena burguesia. Eram espaços nos quais grupos de oposição ou frentes políticas emitiam uma corajosa condenação do regime político (FESTA, 1986, p. 16).

Todavia, quanto ao público leitor, “o estilo, o rebuscamento das expressões, os assuntos, o conteúdo, enfim, fizeram da imprensa alternativa produto de intelectuais, ou atingindo apenas a vanguarda dos movimentos sociais” (CAPARELLI, 1980, p. 46). 
Especialmente a partir de 1974, novas mudanças redesenham o panorama da imprensa: o colapso do milagre econômico, o crescente ativismo político, a reintegração dos primeiros presos políticos à vida civil através da imprensa alternativa, o início da relativa abertura democrática no governo Geisel e a vitória da oposição nas assembléias legislativas estaduais. Nesse cenário, eclodiram projetos editoriais ambiciosos e o boom de jornais alternativos, com diversificação temática e regionalista.

Até 1975, “os jornais alternativos se constituíram não em meros símbolos de resistência da sociedade civil ao autoritarismo, ou a expressão de um movimento ou uma articulação de resistência: eles eram a própria resistência” (KUCINSKI, 1991, p. 54). Neste ano, deflagra-se uma crise do padrão complacente da imprensa convencional e uma forte movimentação social e intelectual, precipitada pela tortura e assassinato de Vladimir Herzog.

A notícia da morte de Herzog corre como um rastilho de pólvora e se forma imediatamente um poderoso movimento de protesto. [...]. A morte de Herzog precipita o protesto que estava atravessado na garganta da intelectualidade paulista desde o começo daquela onda de prisões (KUCINSKI, 2001, p. 35).

Não por acaso, a primeira edição de Versus coincidiu ao assassinato de Herzog e traz estampada na capa títulos como: "Eu fui condenado à morte: confissões de um repórter argentino”, "Eu me condenei à morte: diários de um escritos peruano”, "Nós vivemos na morte: a vida em um hospício mineiro”. O jornal apresenta-se como uma metáfora da própria morte.

Apesar de ser contemporâneo do expressivo jornal Movimento, para Versus, mais do que panfletagem de uma ideologia, o que contava era a experiência vivida, a história que arduamente se tecia no presente, nos solavancos com a ditadura.

Muito embora nunca estivesse alheio à realidade política do País, Versus não abordava diretamente a política "real”, valendo-se de metáforas para se referir ao presente devido à acirrada repressão aos jornais considerados “subversivos” pelo Estado Autoritário. Nas palavras de Bernardo Kucinski:

Versus foi ao mesmo tempo uma alternativa de linguagem, de organização da produção jornalística e de proposta cultural. Em vez do discurso político de Movimento, que o precedeu em alguns meses, usava uma narrativa mítica, operando no plano ideológico através de metáforas culturais e históricas (KUCINSKI, 2003, p. 249). 
Eis que Versus "era uma imprensa voltada para outros aspectos da realidade, como a cultura, a arte, a história, a antropologia, a psicanálise e a psiquiatria. Mostrava nossas raízes comuns latino-americanas, contando histórias, aventuras e dores de nosso século” (CHINEM, 1995, p. 34). Esse é o contexto em que floresce Versus, “uma revista de uma América Latina chocada pelo domínio das ditaduras” (KUCINSKI, 2003, p. 256).

\section{Por uma identidade na América Latina}

Debruçado sobre a memória da América Latina, Versus destacava suas expressões culturais e artísticas, buscando delinear uma identidade partilhada entre os países latinoamericanos. A identidade cultural latino-americana seria, segundo Versus, uma pré-condição para a libertação dos povos latino-americanos, secularmente explorados e marcados por cicatrizes do colonialismo, assolados ainda pelas ditaduras da época.

Seara espinhosa, a questão da identidade é ainda mais intrincada na América Latina, tecida pela articulação complexa de tradições e modernidades, diversas e díspares de um continente heterogêneo (CANCLINI, 1998, p. 28). Na trama dos países latino-americanos estão “sedimentação, justaposição e entrecruzamento” de tradições indígenas, do hispanismo e lusitanismo coloniais, do escravo africano, das revoluções e movimentos independentistas, das ditaduras, da política moderna e, permeando todas essas dimensões, da hibridização das culturas.

Durante muito tempo a heterogeneidade cultural e o sincretismo da América Latina foram considerados obstáculos ao progresso da civilização americana. Os costumes indígenas e africanos eram vistos com racismo e fortes doses de pessimismo em relação à formação do povo latino. O ideal de pureza cultuado no século XIX na Europa era posto em xeque pelas análises das sociedades latino-americanas, onde a miscigenação se transformava num laboratório vivo para a colisão dessas teorias. Nesse sentido, a questão da identidade era vista como uma busca dolorosa para esses povos, matizes pessimistas em relação ao futuro dessas nações perpassavam os estudos europeus, dispondo-nos a uma posição inferior. No século XX, no editorial de Versus lia-se:

Incas, Maias e Astecas, a sua (nossa) memória destruída milimetricamente. Destruir a cultura de um povo é destruir sua moral e sua vontade de liberdade. Todas as culturas índias são espezinhadas. Os índios são escravizados. As escravidões vão se suceder pelos tempos (VERSUS, dezembro de 1976, p. 2). 
Historicamente, a América Latina foi solapada pela continuidade de concepções de humanidade e história provenientes das diversas filosofias européias, desvalorizando o passado, a cultura e a realidade ibero-americana. Quadro dramático que nas relações entre América e Europa nos traz lamentações:

A América é uma utopia, isto é, é o momento em que o espírito europeu se universaliza, desprende-se de suas particularidades históricas e concebe-se a si mesmo como uma idéia universal que, quase milagrosamente, encarna e se fixa numa terra e num tempo preciso: o futuro (PAZ, 1984, p. 151).

Perante essa perspectiva européia, Octavio Paz critica que a América não é um passado, sequer um presente, é uma idéia, uma utopia, “uma invenção”. Para Leopoldo Zea (apud PAZ, 1984), durante muito tempo a questão da América foi monólogo da Europa, uma das formas históricas pelas quais encarnava o pensamento eurocêntrico hegemônico. Atualmente, esse monólogo se transforma em diálogo. "Um diálogo que não é puramente intelectual, mas sim social, político e vital” (PAZ, 1984, p. 151).

A formação da identidade tem laços estreitos com a idéia de diferença. Além de demarcarem fronteiras, as diferenças afirmam e reafirmam relações de poder. Trata-se de uma arena de disputa de legitimidade, tensões simbólicas e atritos reais. A manifestação do poder simbólico está na hierarquização das identidades, na gangorra de louvar e debelar uma identidade em detrimento de outra. Os labirintos identitários da América Latina introduzem uma diferença marcante: a forte hibridização, o que abala e agrava essa disputa de poder.

No hibridismo, a identidade tende a enlear a suposta pureza e insolubilidade das diferentes identidades nacionais, raciais ou étnicas. Isso porque a identidade resultante dessa mistura não é mais integralmente nenhuma das originais “puras”, embora apresente traços de cada uma delas. É preciso pensar a identidade enquanto uma construção social, produto de relações de poder e contextos sócio-históricos - e não como elemento passivo da cultura, como essência.

No caso especifico de Versus a necessidade de uma aproximação dos povos latinos era evidenciada pelo contexto-histórico comum das décadas de 60 e 70, no entanto o periódico foi além ao observar que, em verdade, nosso próprio passado poderia e deveria se constituir num elemento unificador. Contudo, a construção da identidade não diz respeito somente às semelhanças, nesse jogo de forças devemos encará-las pela idéia de “devir”, de tornar-se o híbrido, o mestiço, como movimento e transformação. 
Para Mario Contreras (1996), a América Latina seria uma criação histórica e intelectual que tende a se diferenciar das outras culturas do mundo, em especial da européia e da norte-americana. A constante busca por uma identidade assume nova importância diante de questionamentos como o comportamento cotidiano, o destino das riquezas naturais e humanas na América Latina. Sua emancipação implicaria, pois, na descoberta, criação e reinvenção de novas formas próprias de expressão cultural, histórica, econômica, política, artística etc.

A intensa busca por uma identidade está intimamente relacionada aos diversos processos de assimilação cultural da América Latina, desde a colônia até o presente.

Ainda hoje não temos idéia de quem somos, caminhamos lado a lado, nos esbarramos nos percalços da história, mas continuamos desconhecidos e vivemos num conflituoso embate dialético de não sermos índios, não sermos negros, não sermos brancos, sendo todos ao mesmo tempo (AZEVEDO, 1996, p. 19).

“Todos ao mesmo tempo”. Na teia das relações na América Latina, a hibridização é um fator marcante, entretanto, não deve ser compreendida como um amálgama de diferentes culturas em perfeita harmonia. Para Ianni “a identidade pode ser diferenciada, múltipla, contraditória, em movimento” (IANNI, 2001). Vale dizer que a pluralidade é um agravante, mas não um entrave, na busca por uma identidade latino-americana compartilhada.

O cerne da questão é que a identidade é dinâmica, imbricada nos jogos de forças simbólicas para sua construção e legitimação. Assim, a emergência de diferentes matizes da identidade latino-americana é transitória, “em movimento”. Pretendemos apenas pincelar um elemento-chave para a construção dessa identidade em Versus: a cultura.

Nas suas bem-aventuradas reportagens, ao retratar culturas particularizadas perpassando pelas culturas negra, indígena, mestiças, enveredando para particularidades de Argentina, Brasil, Cuba, Nicarágua etc. - o jornal evidencia similitudes e diferenças entre os povos. A fim de ilustrar essa cobertura especial, citamos as reportagens ${ }^{3}$ :

\section{Argentinaaa}

Em meados de 1974, lentamente, o medo tomou posse dos argentinos. Mas, antes, já havia iniciado sua luta para dominar o corpo e a alma de milhões de pessoas.

Por Tomáz Eloy Martínez • Versus 1• outubro de 1975

\footnotetext{
${ }^{3}$ Todos os artigos estão disponíveis no site: http://www.versus.jor.br/
} 


\section{A ética da conquista}

A história do Frei Bartolomeu de Las Casas, que há séculos tentou proteger a vida dos índios da América e defendeu uma colonização pacífica, contada pelo líder político.

Por José Martí • Versus 5 • agosto de 1976

\section{Gran Tierra}

Do exílio em Barcelona, Eduardo Galeano escrevia para Versus. Aqui, ele relata sua descoberta das secas terras da ponta de Maisí, onde quatro ventos se cruzam e Cuba começa.

Por Eduardo Galeano • Versus 11• junho de 1977

\section{Democracia racial: mito ou realidade?}

Sem a escravidão a estrutura econômica brasileira não teria existido. O escravo foi a espinha dorsal da nova economia. Fazia crescer a riqueza do país, mas pagava com seu suor e sangue a apropriação de tudo pela aristocracia branca.

Por Abdias do Nascimento • Versus 16 • novembro de 1977

\section{Mário Pedrosa: exílio, arte e imperialismo}

“Todas as grandes obras-primas da Europa não são melhores que os grandes monumentos pré-colombianos”, afirma Mário Pedrosa, no retorno do exílio. Por Omar L. de Barros Filho e Júlio Tavares • Versus 17 • dezembro de 1977

\section{Crônicas do país dos males}

Tempos de engano em Hollywood. Uma travessia de Los Angeles, Califórnia. Uma reportagem literária de uma poetisa argentina que andarilhava na Babilônia americana, dourada pela ferrugem de quatro décadas de insônia.

Por Diana Bellessi • Versus 27 • dezembro de 1978

\section{Nicarágua guerrilheira}

O enviado especial de Versus contou como encontrou Somoza no bunker. Foi a última entrevista de Somoza antes da queda, e acabou reproduzida no The New York Times.

Por Hélio Goldsztejn • Versus 31 • abril de 1979 
No Versus, a ênfase destinada à cultura, compreendida como ação e resistência, alicerça essa construção de identidades. Mais do que propor respostas - efêmeras, fugazes, fugidias - o jornal alternativo lança mais questões, acalorando a discussão e, de fato, cumprindo com a proposta da imprensa alternativa: voz aos que não têm voz. Assim, ainda que no confronto com a censura e a repressão, a imprensa alternativa se expressava: "Vozes silenciadas, mas não silêncio de vozes” (REIS FILHO, 2002, p. 450).

Tal presença de questionamentos instigantes pode ser conferida no editorial de sua sétima edição: Versus se define como a busca do fogo que há em toda cinza e questiona: onde está a Nossa América? “Na flauta de nossos índios? Nas ruínas dos Sete Povos das Missões? Na pele de um emigrante nordestino? No medo de um fuzilado de Buenos Aires? Nos escritos de José Martí? [...]” (VERSUS, dezembro de 1976, p. 2).

\section{Considerações finais}

Após analisarmos Versus, duas considerações de destaque são inescapáveis: o jornal, contando com um tom predominantemente cultural, é ilustrativo da imprensa alternativa de vertente existencial, mas não renuncia à crítica política e à resistência - ao contrário, arma-se da cultura como linguagem para dar vazão às suas críticas; o jornal instiga a busca por uma identidade latino-americana, mas não se ilude com uma fórmula ou resposta definitiva que abarque a complexidade e a riqueza da América Latina sob o véu de uma identidade una - ao contrário, questiona ainda mais as raízes e as flores germinadas nessa identidade. Por fim, diríamos que Versus é uma publicação alternativa de resistência que, em sua fase áurea, fez o que seu título postula: um contraponto.

\section{Referências bibliográficas}

AQUINO, Maria Aparecida de. Censura, Imprensa e Estado Autoritário: 1968-1978: O exercício cotidiano da dominação e da resistência: O Estado de S. Paulo e Movimento. Bauru: EDUSC, 1999.

AZEVEDO, Francisca L. N. de. Raízes da América Latina: da colonização à formação dos Estados Nacionais. Rio de Janeiro: Expressão e Cultura/ Edusp, 1996.

BARROS FILHO, Omar de. Versus: Páginas da utopia. Rio de Janeiro: Beco do Azougue, 2007.

CANCLINI, Nestor Garcia. Culturas híbridas: Estratégias para entrar e sair da modernidade. 2a Ed. São Paulo: EDUSP, 1998 (Ensaios Latino-Americanos, 1).

CAPARELLI, Sérgio. Comunicação de massa sem massa. São Paulo: Cortez, 1980. 
CAPELATO, Maria Helena Rolim. Imprensa e História do Brasil. $2^{\mathrm{a}}$ Ed. São Paulo: Contexto/EDUSP, 1994.

CHINEM, Rivaldo. Imprensa Alternativa: Jornalismo de oposição e inovação. São Paulo: Ática, 1995 (Série Princípios).

CONTRERAS, Mario. "Región, Nacionalidad e Integración en America Latina”. In: AZEVEDO, Francisca. L. N. de (Org.). Raízes da América Latina: da colonização à formação dos Estados Nacionais. Rio de Janeiro: Expressão e Cultura/EDUSP, 1996.

FESTA, Regina; LINS DA SILVA, Carlos Eduardo (Orgs.). Comunicação popular e alternativa no Brasil. São Paulo: Paulinas, 1986.

HABERT, Nadine. A Década de 70: Apogeu e crise da ditadura militar brasileira. $3^{\mathrm{a}}$ ed. São Paulo: Ática, 1996 (Série Princípios).

IANNI, Octavio. A era do globalismo. Rio de Janeiro: Civilização Brasileira, 2001.

KUCINSKI, Bernardo. Jornalistas e Revolucionários: Nos tempos da Imprensa Alternativa. São Paulo: Editora Página Aberta: Scritta Editorial, 1991.

. Jornalistas e Revolucionários: Nos tempos da imprensa alternativa. $2^{\mathrm{a}}$ ed. São Paulo: EDUSP, 2003. . O fim da ditadura militar. São Paulo: Contexto, 2001 (Col. Repensando a História).

MICCOLIS, Leila. Catálogo de imprensa alternativa. Rio de Janeiro: Centro de Imprensa Alternativa e Cultura Popular, RioArte, 1986.

PAZ, Octávio. O labirinto da solidão e post-scriptum. Rio de Janeiro: Paz e Terra, 1984.

PEREIRA, Raimundo R. “Vive a imprensa alternativa. Viva a imprensa alternativa!”. In: FESTA, Regina; LINS DA SILVA, Carlos Eduardo (Orgs.). Comunicação popular $e$ alternativa no Brasil. São Paulo: Paulinas, 1986.

REIS FILHO, Daniel Aarão. "Vozes silenciadas em tempos de ditadura”. In: CARNEIRO, Maria Luiza Tucci (Org.). Minorias silenciadas. São Paulo: EDUSP / Imprensa Oficial do Estado, 2002.

TASCHNER, Gisela. Folhas ao vento: análise de um conglomerado jornalístico no Brasil. Rio de Janeiro: Paz e Terra, 1992.

VERSUS. “Aniversário”. São Paulo, nº. 6, outubro de 1976, p. 2.

VERSUS. “Aos Leitores”. São Paulo, nº 7, dezembro de 1976, p. 2. 